\title{
TEMPERATURE DURING CARDIOPULMONARY BYPASS FOR CORONARY ARTERY OPERATIONS DOES NOT INFLUENCE POSTOPERATIVE COGNITIVE FUNCTION: A PROSPECTIVE, RANDOMIZED TRIAL
}

Gilles Plourde, MD, MSc ${ }^{\mathrm{a}}$ Annie Sapin Leduc, $\mathrm{PhD}^{\mathrm{a}}$ Jean E. Morin, MD $^{b}$ Benoit DeVarennes, $\mathrm{MD}^{\mathrm{b}}$ David Latter, $\mathrm{MD}^{\mathrm{b}}$ James Symes, $\mathrm{MD}^{\mathrm{b} *}$ Ross Robbins, $\mathrm{MD}^{\mathrm{a}}$ Nadine Fosset, $\mathrm{RN}^{\mathrm{b}}$ Lucie Couture, $\mathrm{RN}^{\mathrm{a}}$ Alain Ptito, $\mathrm{PhD}^{\mathrm{c}}$

\begin{abstract}
Objective: The objective was to examine the effect of temperature $\left(28^{\circ} \mathrm{vs}\right.$ $36^{\circ} \mathrm{C}$ ) during cardiopulmonary bypass on postoperative cognitive functions in a prospective, double-blind, and randomized manner. Methods: Sixty-two patients scheduled for coronary operations were randomized to warm or cold cardiopulmonary bypass. Preoperative and postoperative (7 days) neuropsychologic evaluations were performed by an observer unaware of cardiopulmonary bypass temperature. Results: Fifty-four patients completed the study (cold bypass, $n=24$; warm bypass, $n=30$ ). Significant $(p<0.01)$ postoperative deterioration for tests of psychomotor coordination and verbal memory was noted in both warm and cold groups, but no differences were observed between groups. Conclusion: Temperature during cardiopulmonary bypass for coronary operations does not influence postoperative cognitive function. (J Thorac Cardiovase Surg 1997;114:123-8)
\end{abstract}

Cent entral nervous system (CNS) dysfunction caused by cardiopulmonary bypass (CPB) is an important cause of morbidity and mortality. ${ }^{1-3}$ Possible causes of CNS damage include microembolization, macroembolization, and inadequate cerebral perfusion. ${ }^{4,5}$ Because hypothermia reduces cerebral metabolism, it has traditionally been assumed that hypothermia during CPB reduces the incidence or severity of CNS damage. ${ }^{6}$

There are at least three reasons to suggest that the cerebral protective effects of hypothermic CPB

From the Departments of Anaesthesia ${ }^{a}$ and Surgery, ${ }^{b}$ Royal Victoria Hospital and McGill University, and the Department of Neurology and Neurosurgery, ${ }^{\mathrm{c}}$ McGill University, Montreal, Quebec, Canada.

Supported in part by a grant from the Heart and Stroke Foundation of Quebec.

G. Plourde is a "Chercheur Boursier Clinicien" of the "Fonds de Recherche en Santé du Quebec."

Presented in part at the 1993 Annual Meeting of the Canadian Anaesthetists' Society, Halifax, Nova Scotia, Canada.

Received for publication July, 31, 1996; revisions requested Sept. 30, 1996; revisions received Jan. 27, 1997; accepted for publication Feb. 13, 1997.

Address for reprints: Gilles Plourde, MD, Royal Victoria Hospital, Department of Anaesthesia, 687 Pine Ave. West, Suite S5.05, Montreal, Quebec, Canada H3A 1A1. (E-mail: mdgp@musica.mcgill.ca.)

*Present address: St. Elizabeth's Medical Center, 736 Cambridge St., Boston, MA 02135.

Copyright (C) 1997 by Mosby-Year Book, Inc.

0022-5223/97 \$5.00+ $0 \quad \mathbf{1 2 / 1 / 8 1 1 2 4}$ may be limited. First, the events with a high risk ${ }^{5}$ for microembolization and macroembolization (aortic cannulation, onset of $\mathrm{CPB}$, end of $\mathrm{CPB}$, aortic decannulation) do not occur during the hypothermic phase of CPB. One could argue, however, that the effects of emboli resulting from aortic cannulation and onset of CPB could possibly be attenuated by subsequent hypothermia inasmuch as hypothermia may be protective even if instituted after the ischemic insult. ${ }^{7}$ Second, modest hypothermia $\left(34^{\circ}\right.$ to $35^{\circ} \mathrm{C}$ ) frequently occurs during the surgical phase preceding CPB and may provide substantial protection against ischemic damage. ${ }^{7-9}$ Third, an arterial filter reduces the number of embolic events during CPB so drastically ${ }^{5}$ that the need for the protective effect of hypothermia would be less.

There are disadvantages associated with hypothermia. Cerebral hyperthermia may occur during rewarming and increase the risk of brain damage. ${ }^{10}$ Disturbances of coagulation, shivering, and increased oxygen consumption in the postoperative period are widely known complications of hypothermia. $^{6}$

Two groups have specifically examined the effects of CPB temperature on postoperative cognitive function. McLean and associates ${ }^{11}$ studied 155 patients (warm $\mathrm{CPB}>34^{\circ} \mathrm{C}, n=78$; cold $\mathrm{CPB} \leq$ $\left.28^{\circ} \mathrm{C}, n=77\right)$ and found no difference between the warm and cold CPB groups. Mora and coworkers ${ }^{12}$ studied 138 patients (warm $\mathrm{CPB} \geq 35^{\circ} \mathrm{C}, n=68$; cold $\mathrm{CPB}<28^{\circ} \mathrm{C}, n=70$ ) and reported a higher 
incidence of postoperative central neurologic deficit for the warm group. The warm group also showed postoperative deterioration on the Digit Span Test. Factors that may account for the prevalence of neurologic events in the warm CPB group of Mora and coworkers ${ }^{12}$ include difference in surgical technique and blood glucose levels. Mora's group ${ }^{12}$ compared warm CPB with retrograde warm blood cardioplegia versus cold $\mathrm{CPB}$ with predominantly antegrade cold, crystalloid cardioplegia. In contrast, McLean and coworkers ${ }^{11}$ used mostly antegrade cardioplegia for both warm and cold groups. Hyperglycemia was more prevalent in the warm group in Mora's study, ${ }^{12}$ and this may have increased the risk of CNS injury. ${ }^{4,13}$ In view of the above discrepancy, further examination of this problem is warranted.

\section{Methods}

Patients. After approval of the Ethics Committee of the Royal Victorial Hospital, 75 patients gave written consent for the study. Patients aged 40 to 70 years, whose native language was French or English, and who were scheduled for elective coronary revascularization were eligible. Exclusion criteria were prior cardiac surgery, history of cerebrovascular disease, severe systemic disease (e.g., pulmonary or hepatic disease or bleeding disorders), or a left ventricular ejection fraction of less than 0.40 .

The treatment order was randomized and each treatment assignment (cold vs warm) was placed in a sealed, sequentially numbered envelope. The perfusionist opened the envelope immediately before the operation. Thirteen patients were excluded before randomization: Unstable angina necessitating an urgent operation developed in six; seven were lost because of change in the planned procedure or last-minute schedule changes. Sixty-two patients were randomized (warm, $n=33$; cold, $n=29$ ).

Neuropsychologic tests. Neuropsychologic assessment was performed 1 to 4 weeks before and 6 to 7 days after the operation. The evaluation included 12 tests and required 60 minutes. When available, another version of the test was used after the operation to diminish practice effects.

To evaluate attention, concentration, and mental tracking, we used the Digit Span Subtest (DIGS) of the Wechsler Adult Intelligence Scale-Revised (WAIS-R). ${ }^{14}$ To assess conceptual and visuomotor tracking, as well as flexibility in shifting the course of an ongoing activity, we used the Trail Making Test (Part B) (TRMB) ${ }^{15}$ The Digit Symbol Subtest (DSYM) of the WAIS-R was used to evaluate complex psychomotor performance. These tests are sensitive indicators of cerebral dysfunction regardless of the locus of the lesion. ${ }^{15}$

Memory and learning for verbal material were assessed with the Associate Learning Task (Paired Words) and the recall of two short stories obtained from the Wechsler Memory Scale ${ }^{16}$ in the immediate (IMPA, IMR1, IMR2) and delayed (DLPA, DLR1, DLR2) condition. Visual memory was evaluated with the delayed recall of the Rey-Osterrieth Complex Figure (DLRY) ${ }^{15}$

Two other subtests of the WAIS-R were administered. The Information subtest (INFO), establishing the subject's general knowledge, was included because it is extremely resistant to the effects of brain injury and cognitive deterioration. It is therefore useful for establishing a person's premorbid ability. The Picture Completion Subtest (PICC) evaluates visual recognition and also requires visual organization and reasoning abilities, because the subject must supply the missing part of the presented material from long-term memory. It correlates highly with the information subtest, in that it also tests remote memory and general information. ${ }^{15}$ Visuospatial organization was evaluated with the copy of the ReyOsterrieth Complex Figure (CORY).$^{15}$ Word fluency was assessed with the Control Oral Word Association Test ${ }^{15}$ (WDFL), used as an indicator of frontal lobe function.

Anesthesia. In addition to their usual cardiac medications, the patients received midazolam $\left(0.07 \mathrm{mg} \cdot \mathrm{kg}^{-1}\right.$ intramuscularly) 60 to 90 minutes before entering the operating room. After placement of electrocardiographic leads and a pulse oximeter, a peripheral intravenous cannula and a radial artery catheter were inserted with the aid of local anesthesia. Anesthesia was induced with sufentanil $\left(6\right.$ to $\left.10 \mu \mathrm{g} \cdot \mathrm{kg}^{-1}\right)$. Pancuronium $\left(25 \mu \mathrm{g} \cdot \mathrm{kg}^{-1}\right)$ and vecuronium $\left(75 \mu \mathrm{g} \cdot \mathrm{kg}^{-1}\right)$ were given to facilitate tracheal intubation. The lungs were ventilated mechanically to maintain the end-tidal carbon dioxide tension at $35 \mathrm{~mm} \mathrm{Hg}$. Anesthesia was maintained with boluses of sufentanil and midazolam. Enflurane was used to treat hypertension or tachycardia. A pulmonary artery thermodilution catheter was inserted after tracheal intubation. Nasopharyngeal and urinary bladder temperatures were continuously monitored and recorded every 5 minutes.

CPB. A bubble oxygenator was used after being primed with $1.5 \mathrm{~L}$ of Ringer's lactate solution, $200 \mathrm{ml}$ of $20 \%$ albumin, $20 \mathrm{gm}$ of mannitol, and $5000 \mathrm{U}$ of heparin. A 20 $\mu \mathrm{m}$ filter was placed on the arterial line and a $40 \mu \mathrm{m}$ filter on the inflow line of the cardiotomy reservoir. Heparin $\left(400 \mathrm{U} \cdot \mathrm{kg}^{-1}\right)$ was given before aortic cannulation and incremental doses were administered to maintain the activated coagulation time, measured every 20 to 40 minutes, above 480 seconds. For warm CPB, the nasopharyngeal temperature was maintained at $34^{\circ}$ to $35^{\circ} \mathrm{C}$. This temperature was chosen because mild hypothermia may protect against ischemia. ${ }^{7-9}$ Flow rate was $2.4 \mathrm{~L} \cdot \mathrm{min}^{-1}$. $\mathrm{m}^{-2}$ for warm CPB. For the cold $\left(28^{\circ} \mathrm{C}\right)$ group, the flow rate was $2.4 \mathrm{~L} \cdot \mathrm{min}^{-1} \cdot \mathrm{m}^{-2}$ at the beginning and end of $\mathrm{CPB}$ and $2.0 \mathrm{~L} \cdot \min ^{-1} \cdot \mathrm{m}^{-2}$ during the hypothermic phase. The oxygen saturation of venous blood was measured every 30 minutes and was maintained at $70 \%$ or above by increasing the flow rate or hemoglobin content (hematocrit value $\geq 0.20$ ). During CPB, arterial pressure was kept between 50 and $100 \mathrm{~mm} \mathrm{Hg}$. If the pressure was below $50 \mathrm{~mm} \mathrm{Hg}$, phenylephrine was given. For mean arterial pressures above $100 \mathrm{~mm} \mathrm{Hg}$, boluses of sufentanil and midazolam were given. If these failed to lower the pressure, enflurane was added via the oxygenator. Rewarming began when the proximal vein graft anastomoses were started. The maximal temperature of the water in the heat exchanger was $39^{\circ} \mathrm{C}$. The nasopharyngeal tempera- 
ture never exceeded $37^{\circ} \mathrm{C}$. Arterial blood gases were sampled at least every hour and maintained within normal limits by the alpha-stat method. Insulin was given if the blood glucose level exceeded $11 \mathrm{mmol} \cdot \mathrm{L}^{-1}$. CPB for the cold group was terminated only after the bladder temperature reached $34.5^{\circ} \mathrm{C}$.

Surgical technique. The surgical technique for both patient groups involved median sternotomy, dissection of the internal thoracic artery, CPB with a cannula in the aortic root, and a single two-stage cannula in the right atrium. Antegrade cardioplegia was administered through an aortic root cannula and a multiport device inserted before the start of CPB. Once CPB was commenced, the aorta was crossclamped and the cardioplegic solution was infused. The aorta was crossclamped only once, for both distal and proximal anastomoses. No retrograde infusion of cardioplegic solution was used.

Intermittent cold blood cardioplegia was used for all patients, except for six patients in the warm CPB group (all patients of surgeon D, Table I), who received continuous warm blood cardioplegia. The cardioplegic solution contained the following (in milliequivalents per liter): sodium 120 , chloride 160 , magnesium 32 , calcium 2.4 , bicarbonate 10 , and potassium 100 or 30 . After aortic crossclamping, cold blood cardioplegia $\left(4^{\circ} \mathrm{C}\right)$ was achieved with a $4: 1$ blood/cardioplegia ratio, the cardioplegic solution having a $100 \mathrm{mEq} \cdot \mathrm{L}^{-1}$ concentration of potassium. The cardioplegic solution was infused until the heart was arrested. Then it was changed to a solution with a $30 \mathrm{mEq} \cdot \mathrm{L}^{-1}$ concentration of potassium. Myocardial temperature measured in the interventricular septum was maintained below $15^{\circ} \mathrm{C}$. Delivery of cardioplegic solution was interrupted periodically for completion of distal and proximal anastomoses or when ventricular distension became a problem. With commencement of the proximal anastomoses, carried out last, the blood cardioplegic solution was warmed to $37^{\circ} \mathrm{C}$.

In both groups, after completion of all anastomoses and evacuation of air from the aorta, the crossclamp was removed and the heart allowed to beat spontaneously. Defibrillation was carried out if necessary, and the patient was weaned from CPB. Once the patient was in stable condition after being weaned from CPB, protamine (1 $\mathrm{mg} / 100 \mathrm{U}$ heparin) was administered.

Postoperative neurologic assessments. Neurologic functions (level of consciousness, motor function, orientation, general behavior) were assessed by one investigator (G.P.) 24 to 36 hours after the operation.

Statistics. The patients' demographic and operative data were compared with $t$ tests for independent samples. Analysis of variance with one grouping factor (CPB temperature) and one repeated factor (time: preoperative vs postoperative) was used to compare the neuropsychologic results. Because of significant differences in the durations of CPB and aortic crossclamping between the warm and cold groups, analysis of covariance with CPB or crossclamp duration as covariate was also used. In no instances did the outcome of the analysis of covariance appreciably differ from that of the analysis of variance. The outcome reported is that of the analysis of variance. The Mann-Whitney $\mathrm{U}$ test was used instead of a $t$ test to compare the dose of phenylephrine during CPB because
Table I. Operative data

\begin{tabular}{lcccccc}
\hline & \multicolumn{2}{c}{ Warm } & & \multicolumn{2}{c}{ Cold } \\
\cline { 2 - 3 } \cline { 5 - 6 } & $\begin{array}{c}\text { No. of } \\
\text { cases }\end{array}$ & $\begin{array}{c}C P B \text { duration } \\
(\text { min })\end{array}$ & & $\begin{array}{c}\text { No. of } \\
\text { cases }\end{array}$ & $\begin{array}{c}\text { CPB duration } \\
(\text { min })\end{array}$ \\
\hline Surgeon A & 17 & 71 & & 11 & 90 \\
Surgeon B & 6 & 58 & & 4 & 84 \\
Surgeon C & 1 & 84 & & 6 & 94 \\
Surgeon D & 6 & 82 & & 3 & 80 \\
\hline
\end{tabular}

the variances were not homogeneous. $\chi^{2}$ Tests with Yates' correction were used to compare proportions. The criterion for significance was 0.01 . All differences at 0.05 level are nevertheless reported. Except for power calculations, ${ }^{17}$ all procedures were done with the program CSS: STATISTICA (version 3.1 for DOS; StatSoft Inc., Tulsa, Okla.).

The sample size required for an $80 \%$ probability of demonstrating that the observed difference between warm and cold CPB is significant at the $p=0.01$ level (one-tail) for a given neuropsychologic test was determined as follows. The mean difference between postoperative and preoperative scores was computed separately for the cold ( $\left.A_{\text {cold }}\right)$ and warm $\left(A_{\text {warm }}\right)$ groups with the respective standard deviations. The difference to be evaluated was thus $A_{\text {warm }}-A_{\text {cold }}$. The pooled standard deviation $\left(S_{\text {pooled }}\right)^{18}$ was used to estimate the population standard deviation. Following Cohen, ${ }^{17}$ we computed "d" as ( $A_{\text {warm }}$ - $\left.A_{\text {cold }}\right) / S_{\text {pooled }}$ and determined the sample size from Table 2.4.1 (page 54), using cubic spline interpolation of the table data.

\section{Results}

Fifty-four patients completed the protocol (warm $\mathrm{CPB}, n=30$; cold CPB, $n=24$ ). Three patients from the warm group were excluded: One had a cerebrovascular accident and two required reexploration for bleeding. Five patients from the cold group were excluded: Two required reexploration for bleeding; one refused postoperative assessment; one was not cooled sufficiently during $\mathrm{CPB}\left(32^{\circ} \mathrm{C}\right.$; only one graft); and one had an acute abdominal disorder in the postoperative period. None of the patients had a perioperative myocardial infarction (defined as a new $\mathrm{Q}$ wave of $2 \mathrm{~mm}$ or more or a creatine kinase-MB fraction of more than 5\%) and none died.

The operative data and patient characteristics are shown in Tables I and II. The only variables that were significantly different between the groups were durations of CPB (18 minutes longer in the cold group) and of aortic crossclamping (14 minutes longer in the cold group) and, predictably, temperature during CPB. The tendency toward longer $\mathrm{CPB}$ duration for the cold group was shown by three of the four surgeons. The differ- 
Table II. Patient characteristics

\begin{tabular}{|c|c|c|c|}
\hline & Warm & Cold & $p$ Value \\
\hline No. & 30 & 24 & \\
\hline $\operatorname{Sex}(M / W)$ & $27: 3$ & $23: 1$ & 0.772 \\
\hline Age (yr) & $58.3(8.7)^{*}$ & $55.9(9.2)$ & 0.330 \\
\hline Educational level (yr) & $11.4(4.1)$ & $11.9(3.6)$ & 0.615 \\
\hline Left ventricular ejection fraction & $0.52(0.08)$ & $0.55(0.07)$ & 0.129 \\
\hline No. of grafts & $3.2(0.9)$ & $3.5(1.2)$ & 0.358 \\
\hline Duration of CPB (min) & $71(21)$ & $89(24)$ & 0.004 \\
\hline Crossclamp time (min) & $58(19)$ & $72(21)$ & 0.014 \\
\hline Temperature before CPB $\left({ }^{\circ} \mathrm{C}\right)$ & $35.2(0.5)$ & $35.3(0.5)$ & 0.382 \\
\hline Lowest temperature during CPB $\left({ }^{\circ} \mathrm{C}\right)$ & $35.8(0.4)$ & $29.0(1.2)$ & 0.000 \\
\hline Temperature at end of $\mathrm{CPB}\left({ }^{\circ} \mathrm{C}\right)$ & $36.3(0.3)$ & $36.3(0.5)$ & 0.950 \\
\hline Glucose during $\mathrm{CPB}\left(\mathrm{mmol} \cdot 1^{-1}\right)$ & $7.3(2.0)$ & $8.2(3.6)$ & 0.303 \\
\hline Dose of sufentanil $\left(\mu \mathrm{g} \cdot \mathrm{kg}^{-1}\right)$ & $9.9(3.3)$ & $9.9(4.0)$ & 0.971 \\
\hline Dose of midazolam $\left(\mu \mathrm{g} \cdot \mathrm{kg}^{-1}\right)$ & $142(82)$ & $113(57)$ & 0.138 \\
\hline Enflurane before CPB (No. of patients) & 21 & 18 & 0.919 \\
\hline Enflurane during CPB (No. of patients) & 5 & 10 & 0.084 \\
\hline Enflurane after CPB (No. of patients) & 11 & 6 & 0.534 \\
\hline Inotropic drugs in operating room & 3 & 0 & 0.319 \\
\hline Phenylephrine during CPB (No, of patients) & 13 & 7 & 0.284 \\
\hline \multirow[t]{2}{*}{ Dose of phenylephrine during CPB $(\mu \mathrm{g})$} & $466(559)$ & $143(79)$ & 0.151 \\
\hline & $\mathrm{n}=13$ & $\mathrm{n}=7$ & \\
\hline
\end{tabular}

*Mean (standard deviation).

ences between the mean CPB durations (cold vs warm) were $19,26,10$, and -2 minutes for surgeons $\mathrm{A}, \mathrm{B}, \mathrm{C}$, and $\mathrm{D}$, respectively. The differences for the mean durations of aortic crossclamping (cold vs warm) were $16,26,1$, and -2 minutes for surgeons A, B, C, and D, respectively. Because the average number of grafts was slightly larger in the cold group ( 3.5 vs 3.2 in the warm group), we computed the duration of crossclamping per graft to eliminate the possible confounding effect of the number of grafts. The mean durations of aortic crossclamping per graft were (mean [standard deviation]) 21.8 (5.8) and 18.2 (3.4) minutes per graft $(p=0.006)$ for the cold and warm groups, respectively. The average dose of phenylephrine for the warm group was more than three times as large as that for the cold group. The difference did not reach significance because of the small number of patients and because the high value for the warm group is mainly attributable to three patients who received 700,1000 , and $2100 \mu \mathrm{g}$ of phenylephrine.

The results of the neuropsychologic tests are shown in Table III. The analyses of variance yielded no significant effect of temperature ( $p$ value ranging from 0.21 to 0.95 ) and no significant interactions ( $p$ value ranging from 0.11 to 0.96 ). The only significant differences concerned the time factor (before vs after the operation). A significant $(p<0.01)$ im- provement in performance was observed with the INFO, PICC, IMR2, and DLRY tests, and an increase in performance on the WDFL test approached significance. Significant performance deterioration occurred only with DSYM and IMPA, and a decrease in performance approached significance with DLPA. The numbers of patients who showed deterioration of one or more standard deviations on at least one test were $16(67 \%)$ and 20 $(67 \%)$ for the cold and warm groups, respectively. For a deterioration of two standard deviations or more, the numbers are nine $(38 \%)$ for the cold group and $11(37 \%)$ for the warm group.

\section{Discussion}

We found no difference in postoperative cognitive function between the warm and cold CPB groups. Postoperative deterioration of psychomotor function (DSYM) and memory (IMPA) was similar in the two groups.

Overall, these results are in agreement with the study of McLean and colleagues, ${ }^{11}$ who also documented a clear postoperative deterioration with the DSYM test, but no difference between patients receiving warm $\mathrm{CPB}$ and those receiving cold CPB. As reported by McLean's group, some test results showed postoperative improvement, probably resulting from practice effects. A few differences in the pattern of postoperative deficits 
Table III. Results of neuropsychologic tests

\begin{tabular}{|c|c|c|c|c|}
\hline Test & Group & Preoperative & Postoperative & Outcome \\
\hline \multirow{2}{*}{ INFO } & Warm & $18.3(6.0) \dagger$ & $19.6(6.1)$ & $\mathrm{I}(0.000)$ \\
\hline & Cold & $19.8(5.2)$ & $21.2(5.5)$ & \\
\hline \multirow[t]{2}{*}{ PICC } & Warm & $15.1(3.1)$ & $16.0(3.2)$ & $\mathrm{I}(0.001)$ \\
\hline & Cold & $14.8(2.4)$ & $15.9(3.3)$ & \\
\hline \multirow[t]{2}{*}{ DIGS } & Warm & $14.4(4.7)$ & $14.6(5.0)$ & NS (0.869) \\
\hline & Cold & $14.6(4.7)$ & $14.6(4.7)$ & \\
\hline \multirow[t]{2}{*}{ DSYM } & Warm & $44.3(11.7)$ & $41.1(11.0)$ & $\mathrm{D}(0.008)$ \\
\hline & Cold & $41.9(8.0)$ & $40.7(8.7)$ & \\
\hline \multirow[t]{2}{*}{ IMR1* } & Warm & $10.3(3.2)$ & $9.3(3.3)$ & NS $(0.387)$ \\
\hline & Cold & $10.3(3.8)$ & $10.6(3.3)$ & \\
\hline \multirow[t]{2}{*}{ IMR2* } & Warm & $8.4(3.6)$ & $9.5(2.8)$ & $\mathrm{I}(0.003)$ \\
\hline & Cold & $8.6(3.5)$ & $10.1(3.8)$ & \\
\hline \multirow[t]{2}{*}{ DLR1* } & Warm & $7.2(3.6)$ & $7.5(3.4)$ & NS $(0.087)$ \\
\hline & Cold & $6.9(3.7)$ & $8.3(3.4)$ & \\
\hline \multirow{2}{*}{ DLR2* } & Warm & $6.5(3.8)$ & $7.1(2.8)$ & NS $(0.079)$ \\
\hline & Cold & $6.4(3.4)$ & $7.4(3.5)$ & \\
\hline \multirow[t]{2}{*}{ IMPA* } & Warm & $13.9(3.6)$ & $13.1(3.1)$ & $\mathrm{D}(0.006)$ \\
\hline & Cold & $15.4(3.3)$ & $13.5(4.1)$ & \\
\hline \multirow[t]{2}{*}{ DLPA* } & Warm & $8.1(1.4)$ & $7.2(2.0)$ & $\mathrm{D}(0.012)$ \\
\hline & Cold & $8.3(1.5)$ & $7.8(2.2)$ & \\
\hline \multirow[t]{2}{*}{ CORY* } & Warm & $26.9(3.1)$ & $26.8(3.0)$ & NS (0.619) \\
\hline & Cold & $25.8(3.5)$ & $26.4(3.2)$ & \\
\hline \multirow[t]{2}{*}{ DLRY* } & Warm & $15.7(5.9)$ & $19.0(4.7)$ & I $(0.000)$ \\
\hline & Cold & $14.5(4.3)$ & $17.1(5.6)$ & \\
\hline \multirow[t]{2}{*}{ WDFL } & Warm & $29.4(10.7)$ & $30.9(10.8)$ & $\mathrm{I}(0.032)$ \\
\hline & Cold & $32.0(9.3)$ & $34.7(9.1)$ & \\
\hline \multirow[t]{2}{*}{ TRMB } & Warm & $103(45)$ & $95(35)$ & NS (0.109) \\
\hline & Cold & $104(37)$ & $97(37)$ & \\
\hline
\end{tabular}

Outcome compares preoperative with postoperative scores for warm and cold CPB groups combined. I, Improvement; $D$, deterioration; $N S$, not significant. The figures in parentheses are the $p$ values for the time factor of the analysis of variance. CORY, Copy of Rey-Osterrieth Complex Figure; DIGS, Digit Span Subtest; $D L P A$, Delayed Recall Associate Learning Task (paired words); $D L R 1$, Delaved Recall Short Story No. 1; $D L R 2$, Delayed Recall Short Story No. 2; DLRY, Delayed Recall of Rey-Osterrieth Complex Figure; $D S Y M$, Digit Symbol Subtest; IMPA, Immediate Recall Associate Learning Task (paired words); IMR1, Immediate Recall Short Story No. 1; IMR2, Immediate Recall Short Story No. 2; INFO, Information Subtest; PICC, Picture Completion Subtest; TRMB, Trail Making Test (Part B); WDFL, Word Fluency Test (Control Oral Word Association Test).

${ }^{*}$ Tests for which different versions were used for preoperative and postoperative testing.

$\dagger$ Mean (standard deviation).

between the two studies deserve comment. McLean and associates ${ }^{11}$ noted an improvement in a test of verbal memory (Buschke tests), whereas we found a deterioration (IMPA). The use of different versions of equivalent tests for preoperative and postoperative evaluation for IMPA may have helped bring out the deficit. Furthermore, McLean's group ${ }^{11}$ found a deterioration with the TRMB, whereas we did not.

Like Mora and coworkers, ${ }^{12}$ we noted significant postoperative deterioration of psychomotor function (DSYM) and of verbal memory for patients in both the warm and cold CPB groups. We observed no change in the Digit Span Subtest (DIGS), whereas Mora's group ${ }^{12}$ reported a mild but significant postoperative deterioration that occurred only in the warm group.

Failure to demonstrate a significant difference between warm and cold CPB raises the issue of statistical power. The issue is perhaps best addressed by examining the two tests that reveal a significant deterioration, DSYM and IMPA. The deterioration was more pronounced for the warm group with DSYM. According to the IMPA results, the deterioration was worse for the cold group. This argues against a clear superiority for either temperature. Nevertheless, the number of patients in each group required to detect the observed difference between the warm and cold group with a power of 0.80 at the 0.01 level (one-tail) is 180 for DSYM and 205 for IMPA.

The longer CPB duration (18-minute difference) in the cold group deserves comment. This longer duration is largely attributable to the longer duration of aortic crossclamping (14-minute difference). It is difficult to explain this difference, which cannot 
be accounted for by a failure of randomization (i.e., slower surgeons being assigned more cold CPB cases) or by a difference in the number of grafts. Despite the documented association between prolonged CPB and increased incidence or severity of CNS dysfunction, ${ }^{4}$ the present difference had no discernible impact on neuropsychologic outcome. The results remained unchanged when the durations of $\mathrm{CPB}$ and of aortic crossclamping were included as covariates in the analysis.

Our study has several limitations. It is based on a small sample of patients with a low risk of complications. We have excluded patients with a history of cerebrovascular disease or severe systemic disease to keep our sample homogeneous. For that reason we also excluded patients who required reexploration for bleeding. We have examined only the early postoperative period because of limited resources. Because the incidence and severity of neuropsychologic dysfunction invariably decreases with time, ${ }^{11,12,19}$ the likelihood that a late assessment would reveal differences not seen on the early assessment is extremely small. Surgeon $\mathrm{C}$ had predominantly cold CPB cases (six of seven cases). This imbalance could have been prevented if a randomization sequence had been prepared for each surgeon. The patients from surgeon $\mathrm{C}$ were not excluded because the randomization protocol had not been violated. The use of bubble oxygenators was dictated by institutional practice. There is no evidence that membrane oxygenators improve cognitive outcome, despite their ability to reduce microembolic events. ${ }^{20}$

We conclude that temperature during CPB does not influence postoperative cognitive function.

We thank J. Sampalis, $\mathrm{PhD}$ (Department of Epidemiology and Biostatistics, McGill University), for advice on statistics; the perfusionists of the Royal Victoria Hospital, the staff of the Department of Anaesthesia and of the Surgical Intensive Care Unit for their collaboration with this study; and S. Caney for typing the manuscript.

\section{REFERENCES}

1. Shaw PJ, Bates D, Cartlidge NEF, et al. Neurologic and neuropsychological morbidity following major surgery: comparison of coronary artery bypass and peripheral vascular surgery. Stroke 1987;18:700-7.

2. Shaw PJ, Bates D, Cartlidge NEF, et al. Early intellectual dysfunction following coronary bypass surgery. Q J Med 1986(New series);58:59-68.
3. Shaw PJ, Bates D, Cartlidge NEF, Heaviside D, Julian DG, Shaw DA. Early neurological complications of coronary artery bypass surgery. Br Med J 1985;291:1384-7.

4. Govier AV. Central nervous system complications after cardiopulmonary bypass. In: Tinker JH, editor. Cardiopulmonary bypass: current concepts and controversies. 1st ed. Philadelphia: WB Saunders, 1989:41-68.

5. Pugsley W, Klinger L, Paschalis C, et al. Microemboli and cerebral impairment during cardiac surgery. Vasc Surg 1990; 24:34-43.

6. Reitz BA, Ream AK. Uses of hypothermia in cardiovascular surgery. In: Ream AK, Fogdall RF, editors. Acute cardiovascular management-anesthesia and intensive care. 1st ed. New York: JB Lippincott, 1982:830-51.

7. Ginsberg MD, Sternau LL, Globus MYT, Dietrich WD, Busto $\mathrm{R}$. Therapeutic modulation of brain temperature: relevance to ischemic brain injury. Cerebrovasc Brain Metab Rev 1992;4:189-225.

8. Todd MM, Warner DS. A comfortable hypothesis reevaluated. Anesthesiology 1992;76:161-4.

9. Berntman L, Welsh FA, Harp JR. Cerebral protective effect of low-grade hypothermia. Anesthesiology 1981;55: 495-8.

10. Nathan HJ, Lavallee G. The management of temperature during hypothermic cardiopulmonary bypass. I. Canadian survey. Can J Anaesth 1995;42:669-71.

11. McLean RF, Wong BI, Naylor CD, et al. Cardiopulmonary bypass, temperature, and central nervous system dysfunction. Circulation 1994;90:250-5.

12. Mora CT, Henson MB, Weintraub WS, et al. The effect of temperature management during cardiopulmonary bypass on neurologic and neuropsychologic outcomes in patients undergoing coronary revascularization. $\mathbf{J}$ Thorac Cardiovasc Surg 1996;112:514-22.

13. Sieber FE, Smith DS, Traystman RJ, Wollman H. Glucose: a reevaluation of its intraoperative use. Anesthesiology 1987; 67:72-81.

14. Wechsler D. WAIS-R manual: Wechsler Adult Intelligence Scale-Revised. New York: Harcourt Brace Jovanovich, 1981.

15. Lezak MD. Neuropsychological assessment. 3rd ed. New York: Oxford University Press, 1995.

16. Wechsler D, Stone CP. Wechsler Memory Scale. Manual. New York: The Psychological Corporation, 1974.

17. Cohen J. Statistical power analysis for the behavioral sciences. 2nd ed. Hillsdale [NJ], 1988.

18. Winer BJ. Statistical principles in experimental design. 2nd ed. Toronto: McGraw-Hill, 1971.

19. Shaw PJ, Bates D, Cartlidge NEF, et al. Long-term intellectual dysfunction following coronary artery bypass graft surgery: a six month follow-up study. Q J Med 1987(New series);62:259-68.

20. Blauth CI, Smith PL, Arnold JV, Jagoe JR, Wootton R, Taylor KM. Influence of oxygenator type on the prevalence and extent of microembolic retinal ischemia during cardiopulmonary bypass: assessment by digital image analysis. J Thorac Cardiovasc Surg 1990;99:61-9. 